MUTH-SENG, Christophe, ROUX, Anthony, LAPORTE, Sébastien, GRAS, Laure-Lise, 2018, Fascia lata numerical model with discrete element method: relationship between micro and macroscale for tensile tests until rupture, Journal of Bodywork and Movement Therapies, Fifth international fascia research congress, BERLIN, ALLEMAGNE, 2018-11-14, 22, 4, Elsevier, pp. 851-852, DOI: 10.1016/j.jbmt.2018.09.020

\title{
FASCIA LATA NUMERICAL MODEL WITH DISCRETE ELEMENT METHOD: RELATIONSHIP BETWEEN MICRO AND MACROSCALE FOR TENSILE TESTS UNTIL RUPTURE
}

Christophe MUTH-SENG ${ }^{1}$, Anthony ROUX ${ }^{1}$, Sébastien LAPORTE ${ }^{1}$, Laure-Lise GRAS ${ }^{2}$

1. Arts et Métiers ParisTech, Institut de Biomécanique Humaine George Charpak, 151 bd de l'Hôpital, 75013 Paris

2. Univ Lyon, Université Claude Bernard Lyon 1, IFSTTAR, LBMC UMR_T9406, F69622, Lyon, France

Contact: laure-lise.gras@univ-lyon1.fr

\section{BACKGROUND:}

Numerical models are useful to better understand the mechanical response of various tissues and materials. With the discrete element method, it is possible to model complex structures with simple elements: small mass elements connected with springs. The macroscopic response of the tissue can then be explained by its microscopic description [1]. We propose to model tensile tests on fascia lata using this method, because of its structure composed of two layers of collagen fibers connected by a proteoglycan matrix [2].

\section{METHODS:}

GranOO (Granular Object Oriented, www.granoo.org) software allowed to build the fascia lata model. Fascia lata microstructure was based on histological results presented in Pancheri et al. [2]. Spherical elements linked with spring bonds were arranged in two oriented layers to create collagen fibers. Extracellular matrix consisted of spring bonds between these layers. Spring bond stiffnesses were calculated from Young moduli of collagen fibers [3] and extracellular matrix [1], and from cross sectional area and initial length of the different links. Failure criterion based on strain [4] was also added to simulate rupture. Tensile tests until rupture [3] were then numerically reproduced. The evolution of force within the different springs was measured.

\section{RESULTS:}

Simulation results suggest that fascia lata behavior is close to brittle material behavior, with almost non-existing yield portion, which is coherent with experimental results. However, load-displacement curve does not present a toe region representative of biological materials. To improve this result, slack must be introduced in the fibers. While load at rupture is also smaller than experimental results, displacement at rupture is similar to the reported values. This suggests that mechanical properties of bonds should be adjusted. One important result is the rupture model: delamination between fiber layers was observed which is representative of what is experienced with ex vivo tests.

\section{CONCLUSION:}

These preliminary results using the discrete element method consist in a first step in our understanding of the relationship between the microstructure and the macroscopic response of fascia lata. Although, adjustments such as slack and accurate mechanical properties are required to go further, this method turns out to be an encouraging new approach.

\section{REFERENCES:}

[1] Roux A, Laporte S, Lecompte J, Gras L-L, Iordanoff I. Influence of muscle-tendon complex geometrical parameters on modeling passive stretch behavior with the Discrete Element Method. Journal of Biomechanics, 49:252-258, 2016. 
[2] Pancheri FQ, Eng CM, Lieberman DE, Biewener AA, Dorfmann L. A constitutive description of the anisotropic response of the fascia lata. Journal of the Mechanical Behavior of Biomedical Materials, 30:306-323, 2014.

[3] Henderson ER, Friend EJ, Toscano MJ, Parsons KJ, Tarlton JF. Biomechanical Comparison of Canine Fascia Lata and Thoracolumbar Fascia: An In Vitro Evaluation of Replacement Tissues for Body Wall Reconstruction. Veterinary Surgery, 44:126-134, 2015.

[4] Shen ZL, Dodge MR, Kahn H, Ballarini R, Eppell SJ. Stress-Strain Experiments on Individual Collagen Fibrils. Biophysical Journal, 95:3956-3963, 2008. 